\title{
Socioeconomic status and lung cancer incidence in men in The Netherlands: is there a role for occupational exposure?
}

\author{
A Jeanne $M$ van Loon, $R$ Alexandra Goldbohm, IJmert Kant, Gerard MH Swaen, \\ Anja M Kremer, Piet A van den Brandt
}

\begin{abstract}
Study objective - To evaluate the influence of occupational exposure to carcinogens in explaining the association between socioeconomic status and lung cancer.

Design - A prospective cohort study. Data on diet, other lifestyle factors, sociodemographic characteristics and job history were collected by means of a self administered questionnaire. Follow up for incident cancer was established by record linkage with a national pathology register and with regional cancer registries.
\end{abstract}

Setting - Population originating from 204 municipalities in The Netherlands.

Participants - These comprised 58279 men aged 55-69 years in September 1986. After 4.3 years of follow up there were $470 \mathrm{mi}-$ croscopically confirmed incident lung cancer cases with complete data on dietary habits and job history.

Measurements and main results - Estimation of occupational exposure to asbestos, paint dust, polycyclic aromatic hydrocarbons, and welding fumes was carried out by two experts, using information on job history from the baseline questionnaire. Socioeconomic status was measured by means of highest attained level of education and two indicators based on occupation. In the initial multivariate analyses of socioeconomic status and lung cancer, adjustment was made for age, smoking habits, intake of vitamin $\mathrm{C}$, betacarotene and retinol, and history of chronic obstructive pulmonary disease or asthma. Additional adjustment for occupational exposure to the four carcinogens mentioned above did not change the inverse association between the level of education and lung cancer risk (initial model: RR highest/lowest level of education $=0.53 ; 95 \%$ CI $0.34,0.82$; additional model: RR highest/lowest level of education $=0.53 ; 95 \%$ CI $0.34,0.84)$. Nor was the association between the two occupation based indicators of socioeconomic status and lung cancer risk influenced by occupational exposure to carcinogens. The effect of occupational exposure on the association between the level of education and lung cancer risk did not differ between ex-smokers and current smokers.

Conclusions - Occupational exposure to asbestos, paint dust, polycyclic aromatic hydrocarbons, and welding fumes could not explain the inverse association between socioeconomic status and lung cancer risk. More research which explicitly addresses possible explanations for the association between socioeconomic status and lung cancer risk is needed.

\section{(f Epidemiol Community Health 1997;51:24-29)}

The risk of lung cancer has very often been found to be inversely related to socioeconomic status. ${ }^{1}$ In studying this association, two possible intermediate factors arise. Firsly, smoking is the most important cause of lung cancer ${ }^{2}$ which is associated with socioeconomic status. ${ }^{34}$ Secondly, occupational exposure to carcinogens is a risk factor for lung cancer ${ }^{56}$ which is also associated with socioeconomic status. ${ }^{7}$ Those occupational categories with a higher risk of lung cancer include metal production and processing workers, road construction workers, and chemical workers. ${ }^{8}$ The increased lung cancer risk within these categories is probably due to exposure to asbestos, polycyclic aromatic hydrocarbons, and metal fumes. ${ }^{8}$ In a previous paper we reported the findings of our research on the association between socioeconomic status and lung cancer and the role of smoking habits and other lifestyle characteristics as intermediate factors. ${ }^{9}$ In addition, we have examined the role of occupational exposure to carcinogens as an intermediate factor in the association between socioeconomic status and lung cancer.

In defining occupational exposure, two criteria were predetermined: the relation between exposure and lung cancer should be substantiated by means of human evidence and the occupational exposure had to occur sufficiently frequently to merit investigation by a population-based prospective study.

Four occupational exposures met these two criteria - exposure to asbestos, paint dust, polycyclic aromatic hydrocarbons (PAHs,) and welding fumes. ${ }^{101112}$ Thus, we have studied the role of occupational exposure to carcinogens in further explaining the association between socioeconomic status and lung cancer after adjustment for relevant lifestyle characteristics like smoking and dietary habits. Furthermore, a history of chronic obstructive pulmonary disease (COPD) or asthma was also included in the analyses, because these respiratory disorders are both related to socioeconomic status $^{13}$ as well as to the lung cancer risk. ${ }^{14}$ 


\section{Methods}

THE COHORT STUDY

The Netherlands cohort study (NLCS) on diet, other lifestyle factors, sociodemographic characteristics, job history, and cancer risk started in $1986 .{ }^{15}$ The cohort included 58279 men aged 55-69 years at the beginning of the study, originating from 204 municipalities in The Netherlands. Data on diet, various lifestyle variables, job history, and other risk factors for cancer were collected by means of a self administered questionnaire. The case-cohort approach was used for reasons of efficiency for data processing and analysis. In a case-cohort approach, cases are derived from the entire cohort, while the person-years at risk are estimated from a random sample of 1688 subjects (subcohort). The subcohort can also be used for studying tumours other than lung cancer. ${ }^{15}$ Since the baseline exposure measurement, the subcohort has been followed up biennially for vital status information. Between September 1986 and December 1990 (4.3 years of follow up) no subcohort members were lost to follow up. Follow up for incident cancer has been established by record linkage with a national pathology register (PALGA) and with all regional cancer registries in The Netherlands. ${ }^{16}$ The current analysis is restricted to microscopically confirmed lung cancer incidence after 4.3 years of follow up. In this period completeness of follow up of the cohort through linkage with the cancer registries and PALGA was estimated to be at least $96 \% .{ }^{17}$ After excluding subjects with self reported prevalent cancer other than skin cancer, 677 lung cancer cases were detected. Prevalent cancer cases other than skin cancer were also excluded from the subcohort $(n=58)$. Furthermore, people with incomplete information about job history or dietary habits were excluded, leaving 1245 subcohort members and 470 lung cancer cases available for analysis.

\section{SOCIOECONOMIC STATUS}

Socioeconomic status was measured by means of highest attained level of education and by means of occupational history, two of the recommended measures for socioeconomic status. ${ }^{18}$ Educational level was classified as primary school, lower vocational school, junior high school, senior high school, higher vocational school, university, and other education. Information about occupational history was coded according to the job coding system of the Central Bureau of Statistics (CBS) frequently used in The Netherlands. ${ }^{19}$ For the present analyses, these CBS codes were aggregated according to occupational sector and required training (EGP) and according to social standing (U\&S). The EGP coding scheme is a reconstruction of the scheme developed by Erikson, Goldthorpe, and Portocarero, ${ }^{20}$ which is still comparable with the original list. ${ }^{21}$ The U\&S score is based on an ordering of occupational titles according to social standing and is also comparable with international classifications. ${ }^{22}$ Other factors relevant to the association between socioeconomic status and lung cancer risk that were measured in the baseline questionnaire are age, smoking habits, intake of vitamin C, beta-carotene and retinol, and history of COPD or asthma. For the construction of the smoking variables the following information is used: smoking status (never/ ex/current), total years of smoking, and the number of cigarettes, cigars, and/or pipes smoked per day. For the multivariate analyses smoking status and pack-years of cigarette smoking for current and ex-smokers were used. Mean individual intakes of vitamin $\mathrm{C}$, beta carotene, and retinol per day were computed by using information about the usual consumption of food and beverages from a 150 item food frequency questionnaire ${ }^{23}$ and information about nutrient contents from the Dutch food composition table of $1986 . .^{24}$

\section{ASSESSMENT OF OCCUPATIONAL EXPOSURE TO CARCINOGENS}

For the exposure assessment by experts, information from the baseline questionnaire of the NLCS was used. This information can be best described as a self administered job history, containing data on job title, name of company, type of company, time period, and information about what was being produced at the department. The construction of the coding system is described in detail elsewhere (Van Loon et al unpublished data).

Briefly, an exposure estimate was assigned to each job by an occupational hygienist (IJK) and an occupational epidemiologist (GMHS), based on information about job title, name of the company, type of company, and time period. Each job was classified into one of four categories: no exposure, possible exposure $(<30 \%$ probability), probable exposure (30$90 \%$ probability), and nearly certain exposure ( $>90 \%$ probability). Furthermore, a weight was assigned to each exposure category as follows: no exposure - weight 0 , possible exposure weight 0.15 , probable exposure - weight 0.6 , and nearly certain exposure - weight 0.95 . Next, the cumulative index of exposure was calculated by multiplying the weight given to each exposure category by the number of years exposed. Subsequently, for each person, all exposures were summed up for the four carcinogens separately.

\section{DATA ANALYSIS}

The prevalence of exposure to the four carcinogens was compared between the case and subcohort groups and between socioeconomic status categories. To study the association between socioeconomic status and lung cancer risk and the role of possible intermediate factors, data were analysed according to the casecohort approach, ${ }^{2526}$ using the GLIM statistical package. ${ }^{27}$ In the multivariate analyses, rate ratios and $95 \%$ confidence intervals for lung cancer were computed for the different socioeconomic status indicators, after adjustment for age, smoking (never/ex/current and pack years of past and current smokers), intake of beta-carotene, vitamin $\mathrm{C}$ and retinol (all as 
Table 1 Occupational exposure to carcinogens: number (\%) of persons who were ever exposed*

\begin{tabular}{lllll}
\hline & Asbestos & Paint dust & PAHs & Welding fumes \\
\hline Subcohort $(\mathrm{n}=1245)$ & $109(8.8)$ & $15(1.2)$ & $66(5.3)$ & $134(10.8)$ \\
Cases $(\mathrm{n}=470)$ & $66(14.0)$ & $17(3.6)$ & $31(6.6)$ & $59(12.6)$ \\
\hline
\end{tabular}

* Only respondents with complete dietary data and job history.

PAHs = polycyclic aromatic hydrocarbons

Table 2 Association between three different indicators of socioeconomic status (SES) and occupational exposure to carcinogens: number (\%) of people in the subcohort who were ever exposed*

\begin{tabular}{lllll}
\hline SES indicator & Asbestos & Paint dust & PAHs & Welding fumes \\
\hline Highest level of education* & & & & \\
Primary school & $15(5.1)$ & $7(2.4)$ & $12(4.1)$ & $19(6.5)$ \\
Lower vocational & $49(18.8)$ & $6(2.3)$ & $29(11.2)$ & $65(25.0)$ \\
Junior high school & $20(5.8)$ & $2(0.6)$ & $14(4.0)$ & $23(6.6)$ \\
Senior high school & $2(1.9)$ & $0(0)$ & $1(1.0)$ & $4(3.8)$ \\
Higher vocational/university & $23(9.6)$ & $0(0)$ & $10(4.2)$ & $23(9.6)$ \\
EGP score†: last occupation & & & & \\
Blue collar & $55(12.1)$ & $12(2.6)$ & $38(8.4)$ & $82(18.0)$ \\
Lower white collar & $12(6.7)$ & $2(1.1)$ & $8(4.5)$ & $14(7.8)$ \\
Upper white collar & $36(9.0)$ & $1(0.2)$ & $17(4.2)$ & $36(9.0)$ \\
Other & $6(2.8)$ & $0(0)$ & $3(1.4)$ & $2(0.9)$ \\
U\&S scoreł: last occupation & $19(8.1)$ & $12(5.1)$ & $10(4.3)$ & $28(11.9)$ \\
1 (low) & $40(12.7)$ & $1(0.3)$ & $28(8.9)$ & $48(15.2)$ \\
2 & $16(4.6)$ & $2(0.6)$ & $13(3.7)$ & $26(7.4)$ \\
3 & $14(7.3)$ & $0(0)$ & $6(3.1)$ & $16(8.4)$ \\
4 & $20(13.1)$ & $0(0)$ & $9(5.9)$ & $16(10.5)$ \\
5 (high) & &
\end{tabular}

* Only respondents with complete dietary data and job history $(n=1245)$. +EGP score: an ordering based on occupational sector and required training.

$¥ U \& S$ score: an ordering based on social standing.

PAHs = polycyclic aromatic hydrocarbons.

Table 3 Rate ratio for lung cancer according to three different socioeconomic status (SES) indicators in multivariate analysis*

\begin{tabular}{|c|c|c|c|c|c|c|}
\hline SES indicator & $\begin{array}{l}\text { No of cases } \\
\text { in cohort }\end{array}$ & $\begin{array}{l}\text { Person years } \\
\text { in subcohort }\end{array}$ & $R R \ddagger$ & $95 \% C I$ & $R R S$ & $95 \% C I$ \\
\hline \multicolumn{7}{|l|}{ Highest level of education } \\
\hline Primary school & 137 & 1214 & $1 \dagger$ & & $1+$ & \\
\hline Lower vocational & 121 & 1097 & 1.28 & $0.89,1.85$ & 1.27 & $0.87,1.85$ \\
\hline Junior high school & 121 & 1442 & 0.94 & $0.65,1.36$ & 0.97 & $0.67,1.41$ \\
\hline Senior high school & 31 & 437 & 0.70 & $0.40,1.21$ & 0.73 & $0.42,1.28$ \\
\hline Higher vocational/university & 57 & 992 & 0.53 & $0.34,0.82$ & 0.53 & $0.34,0.84$ \\
\hline \multicolumn{7}{|l|}{ EGP score $\|$ : last profession } \\
\hline Blue collar & 198 & 1884 & $1 \dagger$ & & $1 \dagger$ & \\
\hline Lower white collar & 55 & 752 & 0.76 & $0.49,1.18$ & 0.82 & $0.52,1.28$ \\
\hline Upper white collar & 144 & 1668 & 0.91 & $0.66,1.25$ & 0.95 & $0.68,1.31$ \\
\hline Other** & 73 & 89 & 0.75 & $0.51,1.10$ & 0.81 & $0.54,1.20$ \\
\hline \multicolumn{3}{|l|}{$\begin{array}{l}\text { Test for trend } \chi^{2} \text { ( } \mathrm{p} \text { value) } \\
\text { U\&S scorett: last profession }\end{array}$} & \multicolumn{2}{|c|}{$0.83(0.36)$} & \multicolumn{2}{|c|}{$0.25(0.62)$} \\
\hline 1 (low) & 102 & 980 & $1+$ & & & \\
\hline 2 & 129 & 1317 & 1.22 & $0.82,1.80$ & 1.23 & $0.82,1.86$ \\
\hline 3 & 120 & 1462 & 0.89 & $0.60,1.32$ & 0.97 & $0.65,1.46$ \\
\hline 4 & 61 & 796 & 0.85 & $0.53,1.36$ & 0.91 & $0.56,1.48$ \\
\hline 5 (high) & 58 & 639 & & $0.72,1.83$ & & $0.73,1.92$ \\
\hline \multicolumn{3}{|l|}{ Test for trend $\chi^{2}$ ( $\mathrm{p}$ value) } & \multicolumn{2}{|c|}{$0.33(0.56)$} & \multicolumn{2}{|c|}{$0.05(0.83)$} \\
\hline
\end{tabular}

* Only respondents with complete dietary data and job history.

† Reference category.

¥ Adjusted for age, smoking behaviour (never/ex/current and packyears), intake of beta carotene, vitamin C and retinol, history of chronic obstructive pulmonary disease (COPD), and asthma.

For age, smoking behaviour (never/ex/current and packyears), intake of beta carotene, vitamin

$\mathrm{C}$, retinol, history of COPD and asthma and exposure to asbestos, paint dust, PAHs and welding

f, reting

| EGP score: an ordering based on occupational sector and required training

* Excluded from test for trend.

t† U\&S score: an ordering based on social standing.

continuous variables), and history of COPD or asthma and after additional adjustment for lifetime exposure to asbestos, paint dust, PAHs, and welding fumes (also as continuous variables). Finally, the role of occupational exposure to carcinogens in explaining the association between socioeconomic status and lung cancer was studied more extensively by conducting a multivariate analysis in the different smoking categories.

\section{Results}

The prevalence of occupational exposure to the relevant carcinogens is presented in table 1. A higher proportion of cases was exposed to asbestos, paint dust, PAHs, or welding fumes. The distribution of socioeconomic status indicators and covariates in the case and subcohort groups after 3.3 years of follow up is presented elsewhere. ${ }^{9}$ Briefly, cases were on average older than members of the subcohort and current smoking was more prevalent in the case group. Cases had a lower educational level and were more often employed in blue collar occupations than members of the subcohort. Finally, the prevalence of COPD or asthma was higher among cases (13\%) than in with subcohort members (10\%).

The prevalence of occupational exposure within each socioeconomic status category in the subcohort is presented in table 2. Occupational exposure to carcinogens was most prevalent among men with lower vocational schooling. The prevalence of occupational exposure to asbestos or welding fumes was also relatively high among men with higher vocational schooling/university education. According to the occupation-based socioeconomic status indicators the prevalence of exposure to asbestos, paint dust, PAHs, or welding fumes was higher among men whose most recent occupation was a blue collar- or a low social standing occupation. The prevalence of exposure to asbestos, PAHs, and welding fumes was also high among men within the highest social standing category.

Table 3 shows the results of the multivariate analyses without and with adjustment for lifetime occupational exposure to asbestos, paint dust, PAHs, and welding fumes. Initially, adjustment was made for age, smoking habits, intake of beta-carotene, vitamin $\mathrm{C}$ and retinol, and history of COPD or asthma. The significant inverse association between the highest level of education and lung cancer risk (RR highest/lowest level of education $=0.53 ; 95 \%$ CI $0.34,0.82$, trend $p<0.01$ ) did not change after additional adjustment for exposure to the four carcinogens (RR highest/lowest level of education $=0.53 ; 95 \%$ CI $0.34,0.84$, trend $\mathrm{p}<0.01)$. The association between the EGP score and lung cancer risk (RR lower white collar/blue collar $=0.76,95 \%$ CI $0.49-1.18$ ) was slightly changed after additional adjustment (RR lower white collar/blue collar = $0.82 ; 95 \%$ CI $0.52,1.28)$. There was no association found between the U\&S score and lung cancer risk.

In a previous analysis of the NLCS data, the inverse association between the highest level of education and lung cancer risk was only found among current smokers. ${ }^{9}$ Therefore, we have studied the effect of occupational exposure to carcinogens on the association between socioeconomic status and lung cancer within the different smoking categories (table 4). Due to the small number of lung cancer cases with complete data in the non-smoking group $(\mathrm{n}=$ 3 ), the analysis could not be carried out for the non-smokers only. We found significant inverse associations between highest level of education 
Table 4 Rate ratio for lung cancer according to highest level of education, by category of smoking in multivariate analysis*, without and with adjustment for occupational exposures

\begin{tabular}{lllll}
\hline & $R R \dagger$ & $95 \% C I$ & $R R \ddagger$ & $95 \% C I$ \\
\hline Ex-smokers & & & & \\
Highest level of education & & & & \\
$\quad$ Primary school & 19 & & 19 & \\
$\quad$ Lower vocational & 1.12 & $0.61,2.07$ & 1.24 & $0.59,2.60$ \\
$\quad$ Junior high school & 1.02 & $0.57,1.84$ & 1.13 & $0.58,2.18$ \\
Senior high school & 1.12 & $0.48,2.58$ & 1.25 & $0.52,30.3$ \\
$\quad$ Higher voc./university & 0.37 & $0.17,0.82$ & 0.41 & $0.18,0.94$ \\
Test for trend $\chi^{2}$ (p v alue) & $7.08(<0.01)$ & $5.41(0.02)$ \\
Current smokers & & & & \\
Highest level of education & & & & \\
$\quad$ Primary school & 19 & & 19 & \\
Lower vocational & 1.49 & $0.92,2.41$ & 1.48 & $0.90,2.43$ \\
Junior high school & 0.86 & $0.54,1.37$ & 0.91 & $0.57,1.48$ \\
Senior high school & 0.58 & $0.29,1.18$ & 0.62 & $0.30,1.25$ \\
$\quad$ Higher voc./university & 0.60 & $0.35,1.03$ & 0.63 & $0.36,1.09$ \\
Test for trend $\chi^{2}$ (p value) & $12.65(<0.01)$ & $9.26(<0.01)$ \\
\hline
\end{tabular}

*Only respondents with complete dietary data and job history.

† Adjusted for age, packyears, dietary intake of beta carotene, vitamin $\mathrm{C}$ and retinol, history of COPD or asthma.

$\ddagger$ Adjusted for age, packyears, dietary intake of beta-carotene, vitamin $\mathrm{C}$ and retinol, history of COPD or asthma and occupational exposure to asbestos, paint dust, PAHs and welding fumes. $\S$ Reference category. might be an explanation for the higher lung cancer risk among men with lower vocational schooling. However, the proportion of men with higher vocational school or university education as the highest attained level of education who were exposed to asbestos was also relatively high - although most were in the lowest exposure tertiles (not presented). This indicates that there is no straightforward association between the level of education and occupational exposure to asbestos. Consequently, this could be explain why adjustment for occupational exposure to asbestos did not change the risk estimates either when occupational exposure was considered as a continuous variable or when categorical variables were used (not presented).

The proportion of men who were ever exposed to asbestos, PAHs, or welding fumes and whose last occupation was a white collar profession or a high social standing occupation was rather high. In about half of the instances the probability of exposure to asbestos in the white collar or high social standing profession was actually assessed to be greater than zero (marine engineer, management of metal industry, or metallurgist). In the remainder, people whose last occupation was a white collar profession or a high social standing occupation were exposed to asbestos, PAHs, or welding fumes during an earlier episode of their job history, in a blue collar profession or a low social standing occupation. This explains the finding that occupational exposure to asbestos, PAHs, or welding fumes was not restricted to men whose last occupation was a blue collar profession or a low social standing occupation. Exposure to paint dust is mainly found among house painters, which appears to be a 'lifelong' occupation in the NLCS. Therefore, exposure to paint dust is only found among blue collar workers and within low social standing jobs. However, because the proportion of house painters in the cohort is small, this will not explain differences in lung cancer risks among socioeconomic status categories.

We found only one study that evaluated the association between social class and lung cancer after adjustment for occupational exposure and tobacco. ${ }^{7}$ The main goal of that study was to assess the proportion of male lung cancer cases due to occupational exposure. The authors reported that social class (based on the last occupation) was only a minor determinant of lung cancer when occupation and smoking habits were controlled for (RR high social class / low social class $=0.8$ ). They did not present information about the association between social class and lung cancer without adjustment for occupational exposure.

The NLCS has been performed in a large sample of the general population aged 55-69 years at baseline. The follow up period of 4.3 years resulted in $\mathbf{4 7 0}$ male lung cancer cases with complete dietary data and job history. The follow up of person-years was $100 \%$ complete and the completeness of cancer follow up was also very high, indicating that selection bias due to loss to follow up is unlikely. Besides, information bias due to random mis- 
classification may have influenced the results. Socioeconomic status is operationalised as the highest attained level of education, EGP score (functional level), and social standing (U\&S score) - the last two both based on the last occupation. In individuals, the highest level of education is stable over time and therefore it will avoid the risk of reverse causation, but this stability can mask important changes in individual circumstances after education has been completed. The occupation based socioeconomic status indicators reflect the more recent situation. However, it is not clear whether knowledge of the socioeconomic status at an older age or younger age is more relevant in studying the association between socioeconomic status and lung cancer risk.

The lifetime occupational exposure to carcinogens was calculated by multiplying the duration of exposure by the likelihood of exposure. The accuracy of the job histories did not allow an estimation of the actual exposure concentrations that were experienced in the past. This may lead to misclassification of exposure. However, since the associations between occupational exposure and lung cancer risk found in the NLCS are comparable with findings from other studies (van Loon et al, unpublished data), it is likely that the exposure assessment reflects the actual exposure to carcinogens to a reasonable extent.

Misclassification of smoking habits may lead to residual confounding. We have measured smoking habits very carefully and included smoking status (never/ex/current smokers) and pack-years of cigarette smoking into the model. Therefore, both duration and amount were taken into account. Moreover, we studied the effect of occupational exposure to carcinogens on the association between socioeconomic status and lung cancer among smokers and exsmokers separately, with comparable results. Consequently, it is not likely that residual confounding of smoking will explain the finding that adjustment for occupational exposure to carcinogens does not influence the association between socioeconomic status and lung cancer risk.

Although more articles have been published on the association between socioeconomic status and lung cancer risk, we did not find papers explicitly addressing possible explanations for these associations. Studies on socioeconomic health differences in The Netherlands point to the role of work related factors like the ability to regulate working conditions, ${ }^{28}$ psychosocial factors, ${ }^{29}$ and differences in social participation and possibilities to control one's fate. ${ }^{30}$ Since these factors are associated with cancer, ${ }^{3132}$ they may also influence the association between socioeconomic status and lung cancer. However, it is not possible to investigate these factors in the NLCS, because there were no items about psychosocial characteristics included in the baseline questionnaire. Also, air pollution ${ }^{3334}$ may play a part in explaining the association between socioeconomic status and lung cancer. For the same reason mentioned above, it is not possible to investigate this in the NLCS.
In conclusion, after adjustment for smoking, dietary habits, and history of lung disease there was still an inverse association between socioeconomic status and lung cancer risk after 4.3 years of follow up. Occupational exposure to asbestos, paint dust, PAHs, and welding fumes could not explain this association.

We want to thank the participants in this study, the regional cance registries (IKA, IKI, IKMN, IKN, IKO, IKR, IKST, IKW, IKZ), PALGA for providing incidence data; $E$ Dorant, $S$ van de Crommert, H Brants, P Florax, J Nelissen, and W van Dijk for assistance in the cohort study and $S$ van den Heuvel from the TNO-PG institute for coding the questions about occupation.

1 Van Loon AJM, Brug J, Goldbohm RA, Van den Brandt PA. Differences in cancer incidence and mortality amon socioeconomic groups. Scand f Soc Med 1995;23:110-20.

2 Tomatis L, ed. Cancer: causes, occurrence and control. Lyon: IARC Scientific Publications 100, 1990.

3 Rosén $M$, Hanning $M$, Wall $S$. Changing smoking habits in Sweden: towards better health, but not for all. Int $\mathcal{f}$ Epidemiol 1990;19:316-22.

4 Sterling TD, Weinkam JJ. Smoking patterns by occupation, industry, sex, and race. Arch Environ Health 1978;37: 313-17.

5 Simonato L, Vineis P, Fletcher AC. Estimates of the proportion of lung cancer attributable to occupational exposure. Carcinogenesis 1988;9:1159-65.

6 Coultas DB, Samet JM. Occupational lung cancer. Clin Chest Med 1992;13:341-54.

7 Pastorino U, Berrino F, Gervasio A, Presenti V, Riboli E Crosignani P. Proportion of lung cancers due to occupational exposure. Int $\mathcal{F}$ Cancer 1984;33:231-37.

8 Jöckel KH, Ahrens W, Wichmann HE et al. Occupational and environmental hazards associated with lung cancer. Int $\mathcal{F}$ Epidemiol 1992;21:202-13.

9 Van Loon AJM, Goldbohm RA, Van den Brandt PA. Lung cancer: Is there an association with socioeconomic status in The Netherlands? F Epidemiol Community Health 1995; 49:65-69.

10 International Agency for Research on Cancer. Overall evaluations of carcinogenicity: An updating of LARC monographs. Vol 1 to 42, Suppl 7. Lyon: IARC, 1987.

11 International Agency for research on cancer. Some organic solvents resin monomers and related compounds, pigments and occupational exposure to paint manufacture and painting. Vol 47. Lyon: IARC, 1989.

12 International Agency for Research on Cancer. Chromium, nickel, and welding. Vol 49. Lyon: IARC, 1990.

13 Bakke PS, Hanoa H, Gulsvik A. Educational level and obstructive lung disease given smoking habits and occupational airborne exposure: A Norwegian community study. Am $\mathcal{f}$ Epidemiol 1995;141:1080-88.

$14 \mathrm{Wu}$ AH, Fontham ETH, Reynolds $\mathrm{P}$ et al. Previous lung disease and risk of lung cancer among lifetime nonsmoking women in the United States. Am $¥$ Epidemiol 1995;141: women in $1023-32$.

15 Van den Brandt PA, Goldbohm RA, Van 't Veer P, Volovics A, Hermus RJJ, Sturmans F. A large-scale prospective cohort study on diet and cancer in the Netherlands. $f$ Clin cohort study on diet and cance

16 Van den Brandt PA, Schouten LJ, Goldbohm RA, Dorant E, Hunen PMH. Development of a record linkage protocol for use in the Dutch cancer registry for epidemiological research. Int $\mathcal{F}$ Epidemiol 1990;19:553-58.

17 Goldbohm RA, Van Den Brandt PA, Dorant E. Estimation of the coverage of Dutch municipalities by cancer registries and PALGA based on hospital discharge data. Tijdschr Soc Gezondheidsz 1994;72:80-84.

18 Liberatos P, Link BG, Kelsey JL. The measurement of social class in epidemiology. Epidemiol Rev 1988;10:87-121.

19 Centraal Bureau voor de Statistiek. Beroepenclassificatie 1984. Lijst van benamingen per beroepencode. Voorburg: CBS, 1985.

20 Erikson R, Goldthorpe JH, Portocarero L. Intergenerational class mobility in three western countries: England, France
and Sweden. British fournal of Sociology 1979;30:415-41.

21 Ganzeboom H, Luijkx R, Dessens J, et al. Intergenerationele klassenmobiliteit in Nederland tussen 1970 en 1985. Men en Maatschappij 1987;62:17-43.

22 Van Berkel-Van Schaik AB, Tax B. Naar een standaardoperationalisatie van sociaal-economische status voor epidemiologisch en sociaal-medisch onderzoek. Sociaaleconomische gezondheidsverschillen nr6. The Hague: DOP, 1990 .

23 Goldbohm RA, Van den Brandt PA, Brants HAM, Van 't Veer P, Al M, Sturmans F, Hermus RJJ. Validation of a dietary questionnaire used in a large-scale prospective cohort study on diet and cancer. Eur f Clin Nutr 1994 48:253-65.

24 Stichting NEVO. NEVO-tabel; Nederlands voedingsstoffenbestand 1986-1987. The Hague: Voorlichtingsbureau voor de voeding. 1986

25 Self SG, Prentice RL. Asymptotic distribution theory and efficiency results for case-cohort studies. Annals of Statistics 1988;16:64-81.

26 Van den Brandt PA, Van 't Veer P, Goldbohm RA, et al. A prospective cohort study on dietary fat and the risk of prospective cohort study on dietary fat and the risk of
postmenopausal breast cancer. Cancer Res 1993;53:75-82. 
27 Baker RJ. GLIM 3.77. Reference manual. Oxford: Numerical Algorithms Group, 1985

28 Schröer CAP, Bullinga RS. Gezondheidsverschillen tussen sociaal-economische statusgroepen: effect van verschillen in leefwijze of arbeidsbelasting? In: Mackenbach JP ed. Sociaal economische gezondheidsverschillen onderzocht. Deel III. Den Haag: DOP, 1991.

29 Ranchor AV. Social class, psychosocial factors and disease. From description towards explanation. Groningen: University of Groningen, 1994. MD Thesis.

30 Joosten J. De invloed van klasse, status en burgerschap op subjectieve gezondheid. Maastricht: University of Maassubjectieve gezondheid. Maas
tricht, 1995. MD Thesis.
31 Horne RL, Picard RS. Psychosocial risk factors for lung

cancer. Psychosom Med 1979;41:503-14.
32 Jahn I, Becker U, Jöckel K-H, Pohlabeln H. Occupational life course and lung cancer risk in men. Findings from a socio-epidemiological analysis of jobchanging histories in a case-control study. Soc Sci Med 1995;40:961-75.

33 Hemminki K, Pershagen G. Cancer risk of air pollution: epidemiological evidence. Environ Health Perspect 1994; 102(suppl 4): 187-92.

34 Barbone F, Bovenzi M, Cavallieri F, Stanta G. Air pollution and lung cancer in Trieste, Italy. Am $\mathcal{F}$ Epidemiol 1995; 